\title{
ISO 9001: Implementation Approach and Impact
}

\author{
Krifi. $\mathrm{B}^{1}$, Mosbah. $\mathrm{A}^{2}$, Jaafar. $\mathrm{M}^{2}$, Chabir. $\mathrm{H}^{2}$, Ben Nasr. $\mathrm{K}^{3}$, Bonert . $\mathrm{G}^{4}$, \\ Perrin. $\mathrm{P}^{4}$ \\ ${ }^{1}$ Higher Institute of Biotechnology, Monastir \\ ${ }^{2}$ Directorate General of Military Health, Tunisia \\ ${ }^{3}$ Cristal North Africa, Tunis, Tunisia \\ ${ }^{4}$ Central Directorate of Health Services of Armed Forces, France.
}

\begin{abstract}
In this study we tried to focus on the ISO 9001 setup approach and its impact in a hospital department (department of pediatric oncology). ISO 9001 certification has become a prerequisite for the commercial promotion of both products and services; it is a sign of acknowledgement that generates benefits. We have noticed that once ISO certification is obtained the company has little effort to make especially if its management system is based on adequate processes that are correlated and well managed which would lead to the professionalism of the function.
\end{abstract}

Key words: ISO 9001 , Quality, hospital environment, audit

\section{Introduction}

With the growing interest triggered by the adoption of quality management systems and considering the advantages that such organization may represent in the optimization of the effectiveness and efficiency of the company( ROA, 1997), it has become necessary for professionals to know and to master the different aspects of the ISO 9001 standard. In fact, with the increase of internal and external pressures on companies, quality emerges as an appropriate and strategic choice for optimizing performances in an evident tendency towards sustainable development and clean production (KHAN, 2006). Therefore it is important to get initiated with the concepts of quality management and to know how to be adapted with the customers' requirements of customers who, being more and more aware of the competitive challenge of globalization, begin to draw the most advantageous profits out of it.

\section{Terms and Definitions:}

-Quality: the aptitude of a set of intrinsic characteristics to satisfy requirements.

-Product: the result of a process.

-Process: Set of correlated or interactive activities that transform inputs into outputs.

-Requirements: Needs or expectations set out, usually implicit, or imposed.

-Customer satisfaction: the perception of the customer on the level of the satisfaction of his requirements.

-Quality management system: a system of management to direct and to control an organization in terms of quality.

-Quality policy: the overall tendencies and intentions of an organization in relation to quality as they are officially set out by the managership.

-Quality objective: what is sought or aimed at, in relation to quality.

-Audit: methodical, independent and documented, process to obtain audit proofs and to evaluate them in an objective way in order to determine to what extent the audit criteria have been fulfilled.

-Effectiveness: the level of the implementation of planned activities and the achievement of the results expected.

-Efficiency: The relationship between the result achieved and the resources used.

-Procedure: specified manner of carrying out an activity or a process.

-Compliance: the satisfaction of a requirement.

-Non-compliance: non-fulfillment of a requirement (ISO $9000: 2000$ ).

\section{History}

The development of fire arms has represented a fundamental change in the perception and the manner of managing armed conflicts .In fact the arms race has become a strategic priority for the different military coalitions and it is in the aim of ameliorating and standardizing industry, not least the military industry, that the first standardization has come out.

Named IEEE «Institute of Electrical and Electronics Engineers », then AESC «American Engineering Standards Committee », it coordinated all the efforts of standardization launched in the early 20th 
century, having as essential goal to struggle against the inaccuracies in the departments of War and of the American Navy. In 1928, it received the name ASA « American Standards Association » which published one of the first standards: "war standard procedure ».

At the international level, in 1926, AESC was the driving force of the movement organised by the English Charles Le Maistre, that led to the creation of the « International Standards Association », ISA. It was a federation gathering non-governmental standardization bodies.

In 1946, just after the Second World War, ASA, AFNOR and the British BSI, participated in London along with standardization institutes from 22 other countries in the creation of the International Standardization Organization (ISO). It was officially created on the $23^{\text {nd }}$ of February 1947 ; from then on it took over from ISA (WIKIPEDIA, 2009).

The naming « ISO » was held in 1946 as the initials of the « International Standardization Organization », but the name of ISO was derived from Greek meaning « equal». The first recommendations came out in 1950. Today ISO includes over 17000 benchmarks /systems of reference all sectors taken into account (ISO, 2007). Figure 1 outlines the ISO sectors of activity.

\section{Dimension of the ISO 9001 certification:}

By the end of 2005, the number of management systems certified to comply with ISO 9001 standard reached a total of 776 608, against 44388 in 2001(ISO, 2005).

Certificates are delivered by more than 750 independent bodies of certification established all over the world. China and Italy hold the first place, with nearly 250000 certificates delivered. (Figure 2).

On the national level, the Tunisian market of certification continues to witness progress: currently there are between 380 and 527 against a dozen companies certified in 2001.

\section{ISO 9001 The Reference Standard :}

Highly imspired by the British standard BS 5750 (GOURLAY, 1994 ; DREW, 2006), ISO 9001 standard was published in 1987. It has rapidly become the reference in terms of certification system and of acknowledgement of the extrinsic quality of a given product. (NORTHEN, 2000). At the beginning, it was fragmented into three standards according to the field of activity covered by the quality system. Over time, it has been simplified into a single standard that has brought together all sectors. The final version published in 2008 is even more adapted to the present socio-economic evolution by cultivating more and more the philosophy of total quality (CHAN, 2002), a concept that preaches the maximum of satisfaction and the maximum of efficiency (BURCHER, 2002). However, in addition to the necessity of satisfying the classical requirements of older versions, the new update of ISO 9001 standard has emphasized the necessity of mastering the whole production chain starting from the selection of suppliers up to after-sales service.

Nonetheless, this version has kept the structure of 2000 version (figure 3) which divides into 4 chapters the requirements that the company must fulfill in terms of organization and of the operation of its services in order to comply with a policy called « quality politics » and thereby to achieve a set of objectives, namely quality objectives, while remaining completely flexible and compatible with the other management systems and the other managerial approaches in relation to ISO 4001, HACCP or the six sigma method for example (WESSEL, 2004 ; TSAI, 2009 ; WALLAS, 2001).

\section{Principles of ISO 9001 Standard}

ISO 9001 Standard is inspired from great managerial principles that have made the success of multinational companies and that have always been claimed by experts in the social, economic and political fields. It has a multidimensional and global view of the managerial approach through the enactment of certain fundamental principles:

- Customer Focus :

Institutions depend on their customers; therefore they should understand their present and future needs, meet customer requirements and try hard to anticipate their expectations.

- Leadership :

Leaders establish the purposes and the direction of the institution. They should create and maintain an internal environment in which people can fully be involved in achieving the objectives of the organization.

- Involvement of the Personnel

People at all levels are the essence of the organization and a total commitment from them permits to use their skills to the benefit of the organization.

- Process Approach :

An expected result is reached more efficiently when related resources and activities are managed as a process.

- Management by system approach : 
Identifying, understanding and managing interrelated processes as a system that contributes to the effectiveness and the efficiency of the organization in order to achieve its objectives.

- Continuous improvement :

The continuous improvement of the overall performance of an organization should be a permanent objective.

- Factual Approach to decision-taking :

Effective decisions are based on the analysis of data and information.

- Mutually beneficial relations with suppliers :

An organization and its suppliers are interdependent and mutually beneficial relationships enhance the capacities of both to create value. (ISO $9000: 2000$ )

\subsection{Process Approach:}

\section{Implementation Approach of ISO 9001:}

Like any certifiable standard, ISO 9001 standard is based on fulfilling a set of requirements or responsibilities indicated in the normative text with a minimum of formality (quality manual, procedures, specifications, forms, etc.).

It consists in setting up, maintaining and improving a structure based on organization and on a process approach (BHUIYAN ,2004). The latter, confirmed in the 2008 version, constitutes a fundamental element in the conception, development and improvement of a quality management system (ISO 9001 : 2008). Any activity within the company is a set of transformations of a raw material, catalyzed by the inputs, which leads to by the end to an added value aiming at the achievement of objectives expressed by «ouput elements» that are quantifiable, measurable and that take into account customer satisfaction. The input element of a process may be the output element of another; that's how we manage, by transverse approach, to identify interactions between the different structures, often compartmentalized, of a company and to manage and optimize in that way their functioning.

This organization that integrates the job approach in a system approach encourages the institution to rethink its business, its organization, its resources and the expectations of its customers. It allows a much greater legibility of the organization, improves communication and facilitates the allocation of means in a non-partitioned logical cross. (PALMER, 1999 ; KAUR, 2006). It puts the institution in a learning position directed towards continuous amelioration (LONGIN, 2004). Figure 4 shows organisation based on the process approach and management by system approach.

The deployment of a quality system complying with the ISO 9001 standard goes necessarily through the identification of processes (ISO 9001, 2008), the decompartmentation of authorities with a rational distribution of responsibilities in a climate of transparency, objectivity and continuous motivation. This can never take place without difficulty or resistance (ESCANCIANO, 2001) from the company naturally resistant to any reform that may call into question its level of organisation and of efficiency (KANOLD, 2008). Nonetheless, big companies, in particular those oriented towards exports, having more resources and being more concerned with the quality of their products, become more easily involved in this challenge than small companies which do not have enough experience and resources to establish and maintain a proactive quality system (PALMER, 1999., BHUIYAN, 2004., ESCANCIANO, 2001, KARIPIDIS, 2002, GHOBADIAN, 1997).

Because of its conception, quality system promotes good management practices and thus increases the ability of the company to achieve its objectives (ROA, 1997 ; KARIPIDIS, 2009).

The various processes of an institution are generally classified into three categories:

- Processes of management or of managership: they apply to aspects within the responsibility of the leading team (strategy, policy, planning, resources, communication), having a direct impact on the functioning of the institution and its dynamic of amelioration; it directs and ensures the cohesion of the other processes in relation to the policy and objectives of the company, to quality system planning and to its regular review, to resource management and to communication.

- Processes of implementation called operational processes (job): they apply to activities related to the flow of product implementation, from marketing to sale.These processes have a direct impact on customer satisfaction .

- The support processes (backing) : they apply to the provision of means and resources necessary for the good development of the implementation processes. They do not create any value directly perceptible by the customer although they are necessary for the proper functioning and to the durability of the company.

These processes answer the WHAT and WHY questions. We shall see later that the procedures answer the WHO, even WHEN, WHERE and HOW questions.

\subsection{Example of a quality system in a hospital environment}

Like all sectors of human activity, the medical field falls in perfectly with quality management, 
provided that we define reasonably the processes involved. Figure 5 schematizes the interactions between the different processes of a pediatric oncology department.

The mapping of processes is the systemic representation of processes permitting the achievement of the mission. The implementation processes or the "job" processes include the "diagnosis "processes composed of 6 therapeutic processes:

- Process of chemotherapy;

- Process of complications and accidents ;

- Process of implants ;

- Process of multidisciplinary consultation: multidisciplinary meetings, request of a second advice, videoconferencing, etc ;

- Process of technical wherewithal : radiotherapy, surgery, anesthesia and resuscitation, cell therapy, etc ;

- Process of long-term aftercare: study of after effects, evaluation of the quality of life.

The three associated therapeutic processes are the following:

- Process of networks: local hospitals, home medical care, doctors, private paramedics, etc.) ;

- Process of support care: nutrition, psycho-oncology, pain, palliative care and mourning, rehabilitation and side effects of the treatment;

- Process of child project: taking into account social, family and relational dimension: schooling, entertainment, family relationships, child, parent associations.

Very often, the representation of processes is not linear. This is the case in a clininal department where interactions between processes are complex and highly interdependent.

However, the procedures can often be transposed to a flow chart in more linear and consequently more legible logic. (See table I).

The flow chart schematizes the role of the actors (who, what, how) in a process. Decision-taking is represented by diamonds. Ellipses are the processes taken before and after. Traceability documents stemming from actions should equally be represented. Registrations are achieved either in specific forms or under the form of other documents: parental consent signature, medical report, mail, etc.

Operating modes or instruction forms associated with this procedure specify the appropriate method to follow in order to achieve the tasks.

A documentation booklet (FD ISO/TR 10013) defines the managerial guidelines for the documentation of quality management system, particularly regarding the procedures, work instructions and forms that we have just mentioned.

\section{Audit of Quality Management System:}

The audit is a methodical review that permits to determine the effectiveness and the efficiency of the measures established by the company as well as the deviations from the reference standard. The implementation of these management system audits is managed by an international standard ISO $19011: 2002$.

Like other means such as the monitoring and measurement of processes and products, the audit represents an instrument of progress available to leading team, a tool to improve the efficiency of processes, to facilitate communication and to better sell the company to customers and to suppliers (LONGIN, 2004).

\section{Impact of ISO 9001 System:}

The structure, its principles and its approach predispose this system to a potentiation of ecomonic, human and environmental performances. We are, a priori, far from thinking that ISO 9001 system could have a negative impact on the development of certified companies. Unfortunately, this is not always the case.

In fact, the manner in which the company designes the system and mainly the manner in which it manages it is crucial for the success of the quality project. Contrary to popular belief, certification is not an aim in itself but a means to achieve compliance and promote excellence. This strategy must necessarily be subtended by a strong commitment from the leading team. This has been one of the key points of the 2000 version of ISO 9001 standard; hence the importance of implementing quality culture at all levels of the company and particularly at the level of the leadership without whom such a project would be counterproductive. The ISO 9001 certification has become a prerequisite for the commercial promotion of products and services; it is a sign of acknowlegement that generates internal benefits (better internal organisation, better communication, better production control, better management of non conformities and a reduction of the cost of poor quality in addition to external benefits (commercial promotion, access to the international market and enhancing the reputation of the company) (RAJENDRAN, 2004 ; KARIPIDIS, 2009 ; DRAW, 2006).

The perception of these benefits is often mixed. It depends on the socio-economic reality of the company.Thus, 30 per 100 of the Saudi and Spanish companies declare being unsatisfied or indifferent with regard to the implementation of the quality system (ESCANCIANO, 2001; MAGD, 2004) while 
GOTZAMANI (2002) concludes that companies that undertake a quality procedure are those that register the highest benefits.

The argument over the cost and profits of the quality procedure is far from being over; it continues to fuel controversy. In fact, several authors believe that quality management system has no significant impact on the performances of the company but on the contrary that it reduces its competitive potential through the increase of formalism at the expense of good management practices and of the quality of the end product: an opinion shared then by the president of the European commission (ZUCKERMAN, 1998 ; RAJENDRAN, 2004).

In fact, the cost of the procedure of certification is not easy to endure for small and medium-sized companies, contrary to multinational companies which are advantaged in this regard due to the disproportion of financial and human resources between the two categories of companies (BOLTON, 1997). Cost distribution is largely dominated by the expenses of the internal reconfiguration of the company ( 60 per100 of the total cost) (MAGD, 200 3).

Moreover, such a procedure may reveal financially failing (in 7, 3 per 100 of the cases). According to ESCANCIANO (2001), the major barriers to the success of the quality procedure are the complexity of the procedures and the vast number of registrations (39 per 100), resistance to change (32.3 per 100) and the lack of experience in quality management (28.8 per 100), hence the need to support small and medium-sized companies in their certification process: this is the case in many countries that have established mechanisms of assistance for the implementation of quality systems. In Tunisia, the national program of quality promotion is the best example of public assistance. In conclusion it would be irrational to generalize the failure or the success of the system of quality management to all professionals: its outcome is the result of several factors both internal and external to the company and it is thanks to a concrete commitment and realistic planning that the company may change its socio-economic context, a context that is becoming more and more uncertain.

\section{References:}

[1]. ANONYME. 2007. Leader auditor ISO 9001 treening course, international Treening course Tunisia veritas October 2007.

[2]. BURCHER P. 2002. Quality management resource pack, Postgraduate programme, Aston Business School Birmingham.

[3]. BHUIYAN N., ALAM N. 2004. ISO9001: 2000 Implementation-the North American experience, International Journal of Productivity and Performance Management; 2004; 53, 1/2; ABI/INFORM Global, p. 10.

[4]. CHAN Y. K., KAM J., NEAILEY K. 2002. How IMS can achieve ISO 9001:2000 certification, The TQM Magazine; 2002; 14, 6; ABI/INFORM Global p. 345.

[5]. ESCANCIANO C., FERNANDEZ E., VAZQUEZ C. 2001. ISO 9001 certification and quality management in Spain: results of a national survey, The TQM Magazine; 2001; 13,3; ABI/INFORM Global p.192.

[6]. GHOBADIAN A. GALLEAR D. 1997. TQM and organization size, Internal Journal of Operation \& production Management, Vol.17 N², p.121-63.

[7]. WESSEL G. BUCHER P. 2004. Six sigma for small and medium-sized enterprises, The TQM Magazine; 2004 16,4; ABT/INFORM Global, p.264.

[8]. RAJENDRAN C., ISSAC G., ANANTHARAMAN R.N. 2004. Significance of Quality Certification: The Case of the Software Industry in Indi, The Quality Management Journal; 2004; 11, 1; ABI/INFORM Global, p.8

[9]. ISO 2001. ISO/TC 176 module d'introduction et de soutien: guide sur les exigences de documentation de l'ISO 9001:2000, Document ISO/TC 176/SC 2/N 525R Mars 2001, Genève.

[10]. ISO 2000. ISO 9000: 2000 norme de management de la qualité principes essentiels et vocabulaire. 2000, Genève.

[11]. ISO 2000. ISO $9001: 2000$ système de management de la qualité exigences. 2000., Genève.

[12]. ISO.2008. ISO 9001: 2008 quality management system requirements. 2008, American National Standard.

[13]. ISO 2007. Le système ISO le partenaire de la confiance, Rapport annuel ISO 2007, Genève.

[14]. ISO 2005. The ISO survey-2005, The ISO survey certification 2005, Geneva.

[15]. ISO 2002. ISO 19011Lignes directrices pour l'audit des systèmes de management de la qualité et/ou de management environnemental. Décembre 2002. Genève

[16]. ISO 2006. ISO/TR 10013. Lignes directrices pour la documentation des systèmes de management de la qualité.Mars.2006. Genève

[17]. MAGD H., KADASAH N., CURRY A. 2003. ISO 9000 implementation: A study of manufacturing companies in Saudi Arabia, Managerial Auditing Journal; 2003; 18,4; 1BI/INFORM Global, p.313.

[18]. NORTHEN J.R. 2000. Quality attributes and quality cues : effective communication in the United Kingdom fresh meat supply chain, British Food Journal, Vol. 102, p.230-45.

[19]. DREW E., HEALY C. 2006. Quality management approaches in Irish organizations, The TQM Magazine Vol. 18 No. 4,2006, p. $358-371$.

[20]. KANOld J., HAlle P., PAillard C., MERlin E,. DAVID A,. LEVAllois S., ROUDEIX, D,. DUGUE, F., LACAZE, C., MORISSET1, C,. SOUQUIERE, V., DEME F. 2008. Implementation of quality assurance program ISO 9001 in a department of paediatric oncology, Archives de Pédiatrie 2008;15:122-134.

[21]. KAUR K. 2006. Quality management service at the University of Malaya library, Library Management. Vol $27 \mathrm{~N}^{\circ} 4,2006$ p. 249 256.

[22]. PALMER E,. LEE K. S. 1999. An empirical examination of ISO 9000-registered companies in New Zealand, Total Quality Management; 10, 6; ABI/INFORM Global p.887.

[23]. ROA S.S., RAGU-NATHAN T.S., SOLIS L.E. 1997. Does ISO 9000 have an effect on quality management practices? An international empirical study, Total Quality Management; Dec 1997; 8,6 ABI/INFORM Global p.335.

[24]. SROKA S. 2000. Business excellence in project oriented company - case study, transsystem S A presentation made to the 15th IPMA world congress on project management, London, UK, 22-25 May, 2000.

[25]. TSAI W-H., WEN-CHIN CHOU W-C. 2009. Selecting management systems for sustainable development in SMEs: A novel hybrid model based on DEMATEL, ANP, and ZOGP, Expert Systems with Applications 36 (2009) 1444-1458. 
[26]. KHAN Z. 2006. Cleaner production: an economical option for ISO certification in developing countries, Journal of Cleaner Production 16 (2008) 22-27.

[27]. GOURLAY R. 1994. Seeking credibility for quality standards, Financial Times. 12 April.

[28]. WALLACE C., WILLIAMS T. 2001. Pre-requisites: a help or a hindrace to HACCP?, Food Control 12 (2001) 235-240.

[29]. WIKIPÉDIA 2009. Organisme international de normalisation. internationale de normalisation, Wikipédia.mht consulté le 31 mars 2009.

[30]. KARIPIDIS P,. ATHANASSIADIS K,. AGGELOPOULOS S,. GIOMPLIAKIS E. 2009. Factors affecting the adoption of quality assurance systems in small food enterprises, Food Control 20 (2009) 93-98.

[31]. GOTZAMANI K., TSIOTRAS G.C. 2002. The true benefits behind ISO 9000 certification: Their effect on the overall certification benefits and long term contribution towards TQM, International Journal of Quality and Reliability. Management, 19(2), 151-169.

[32]. ZUCKERMAN A. 1998. GM enforces QS-9000 mandate, Purchasing. 125: 131-132.

[33]. BOLTON A. 1997. Quality management systems for the food industry: A guide to ISO 9001/2, London: Blackie Academic and Professional.

[34]. LONGIN P,. DENET H. 2004. Construisez votre qualité, Dunod Paris 2004 ISBN 2100007086X.

Table I: Flow chart of the « Diagnosis » process in a pediatric oncology department (KANOLD, 2008).

Table 1: "Diagnosis" Process

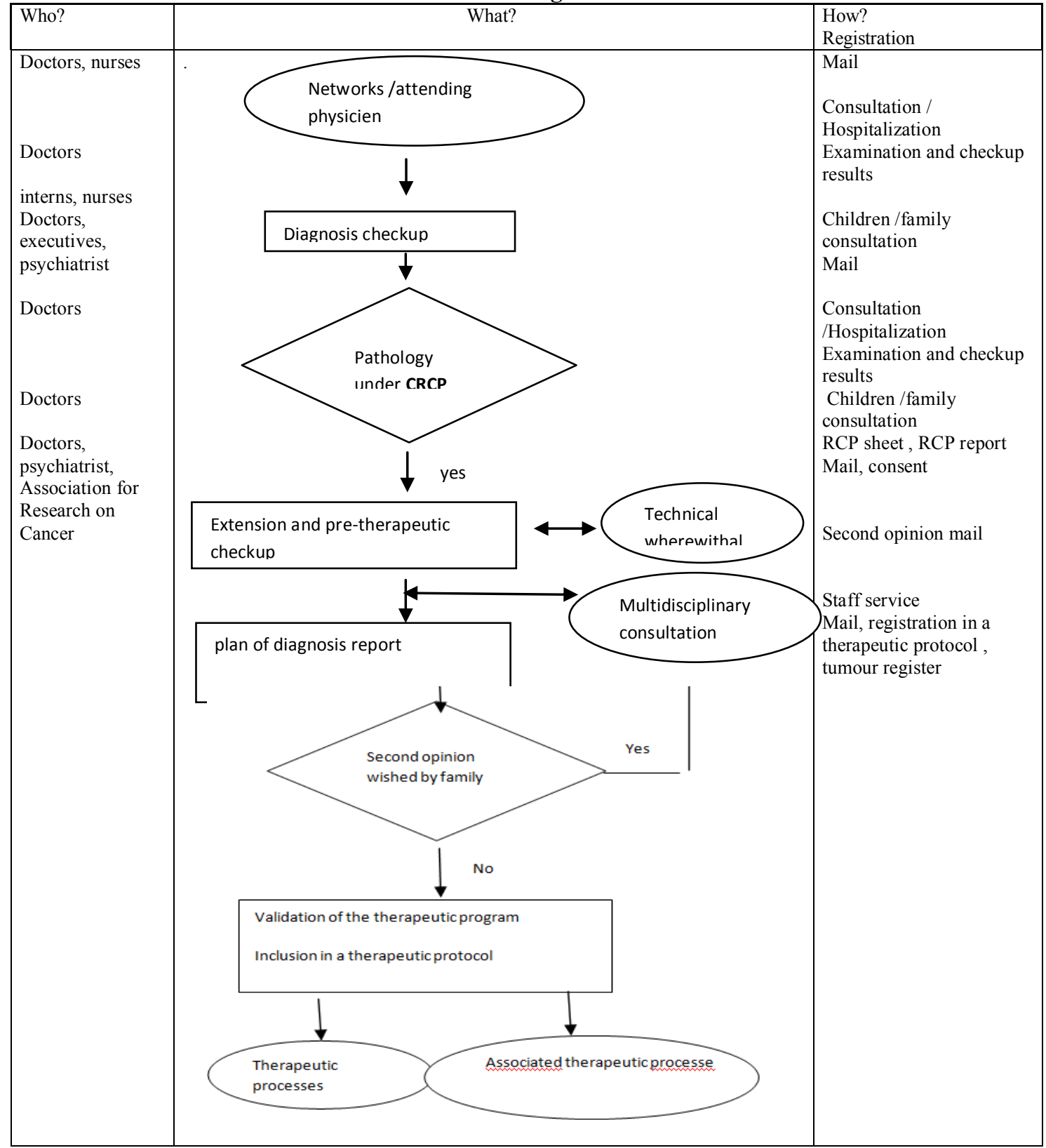




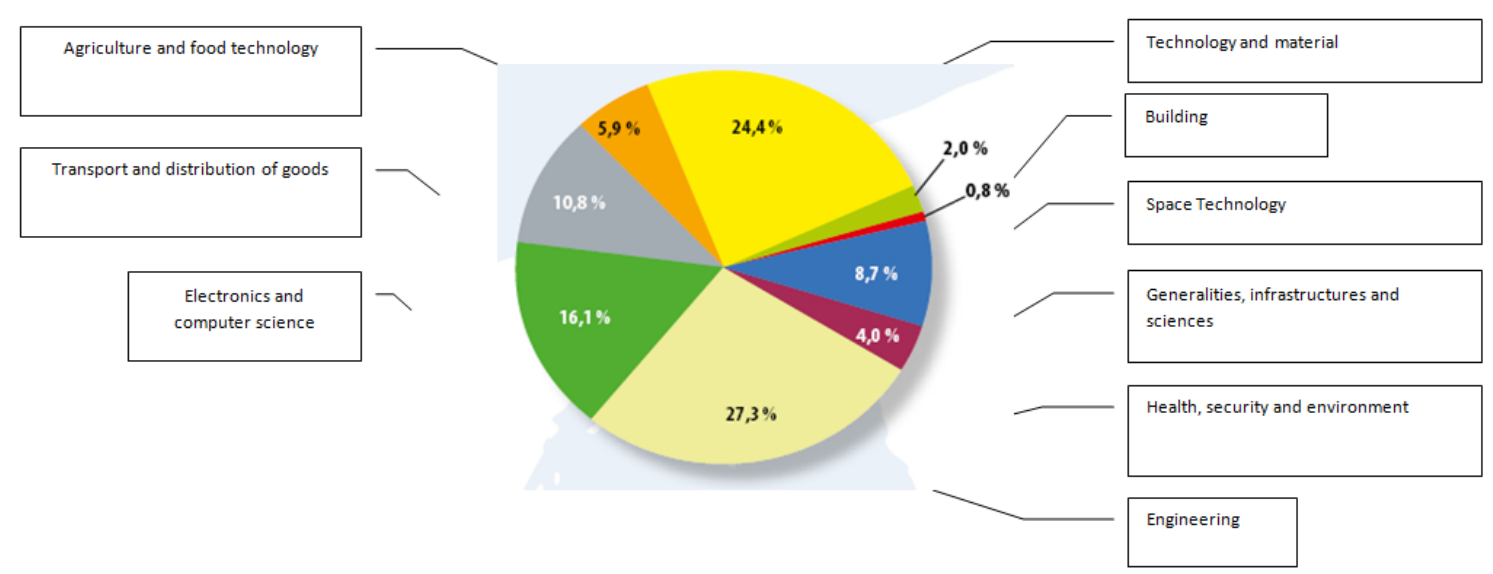

Figure 1 : ISO Standardization Effort, by sector of activity (ISO, 2007).

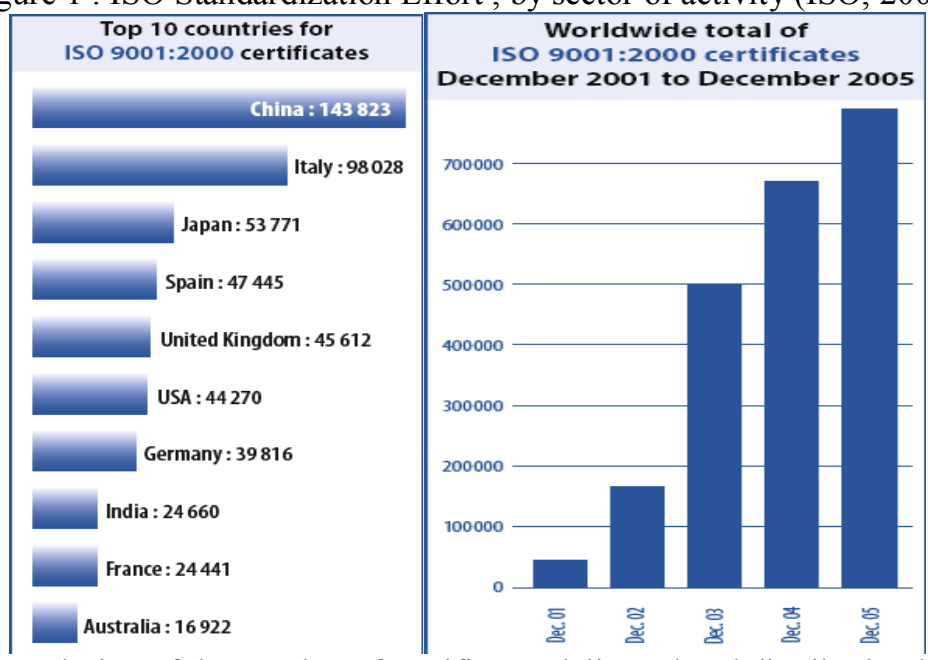

Figure 2: Evolution of the number of certificates delivered and distribution by Country

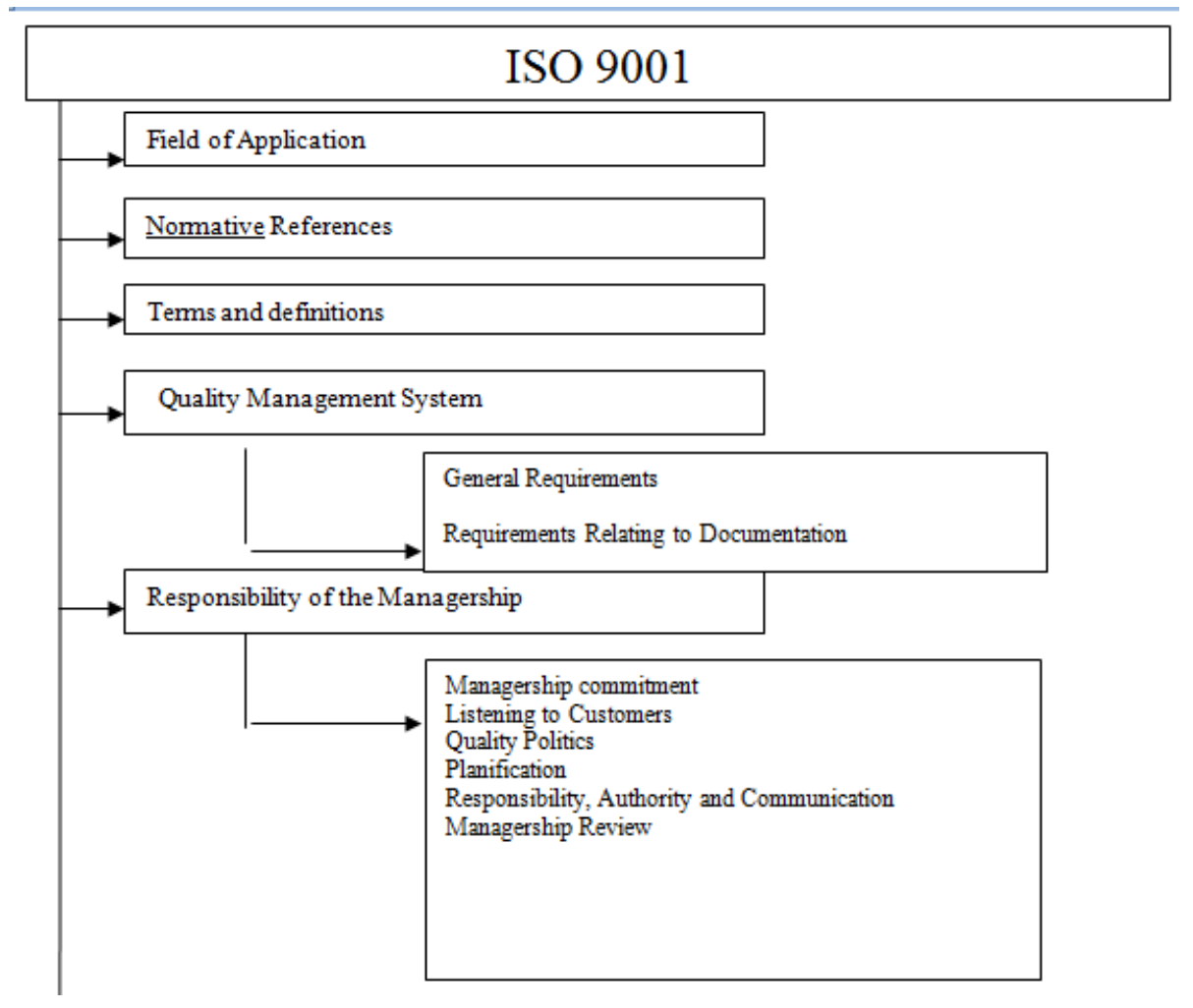




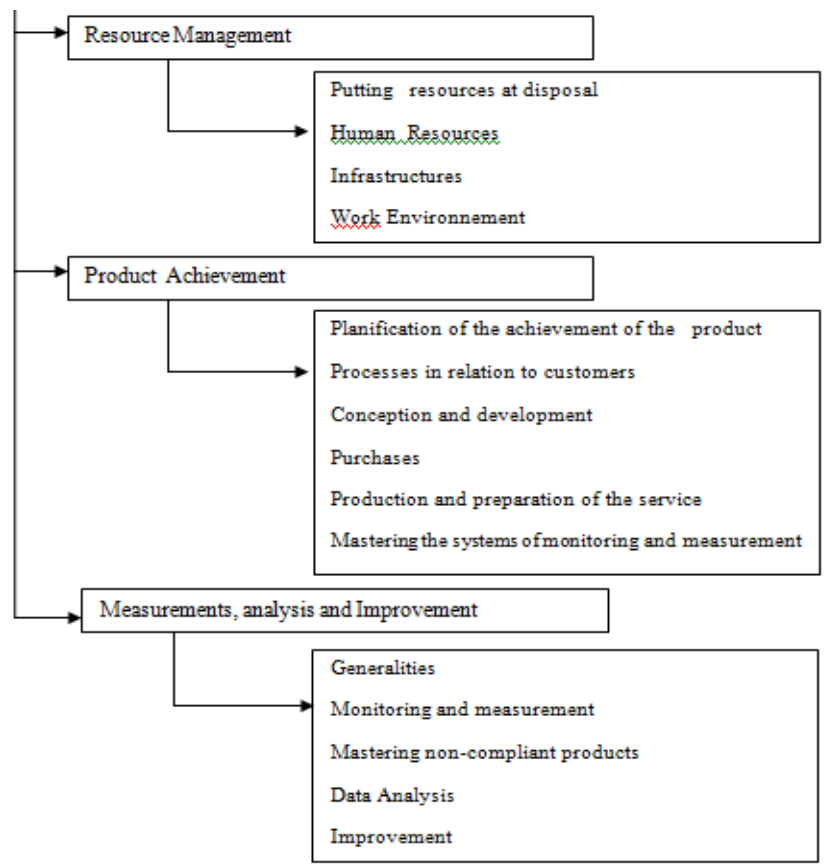

Figure 3 : Structure of ISO 9001 Standard : 2008

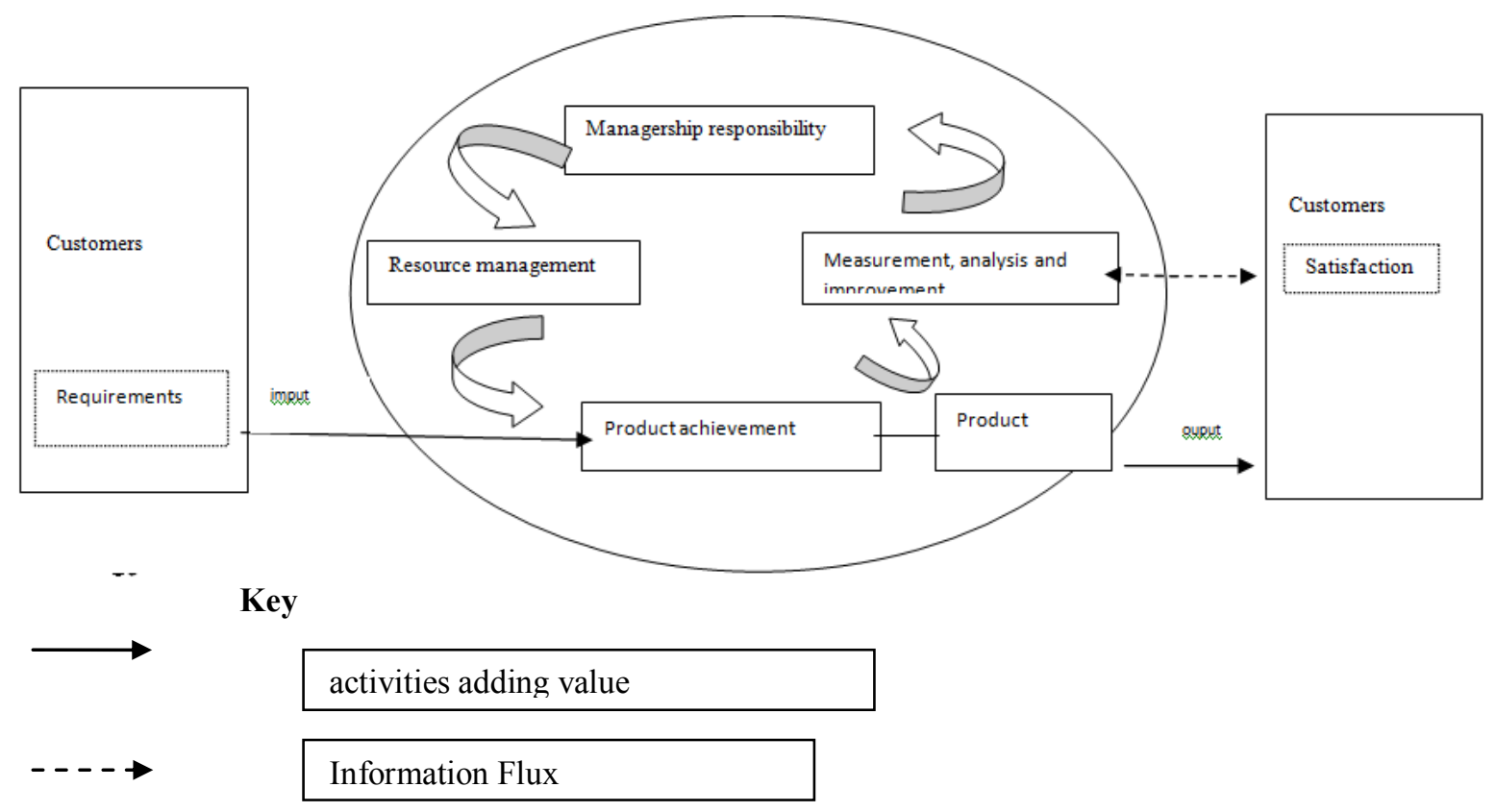

Figure 4: Model of quality management system based on the process (ISO 9001, 2008) 


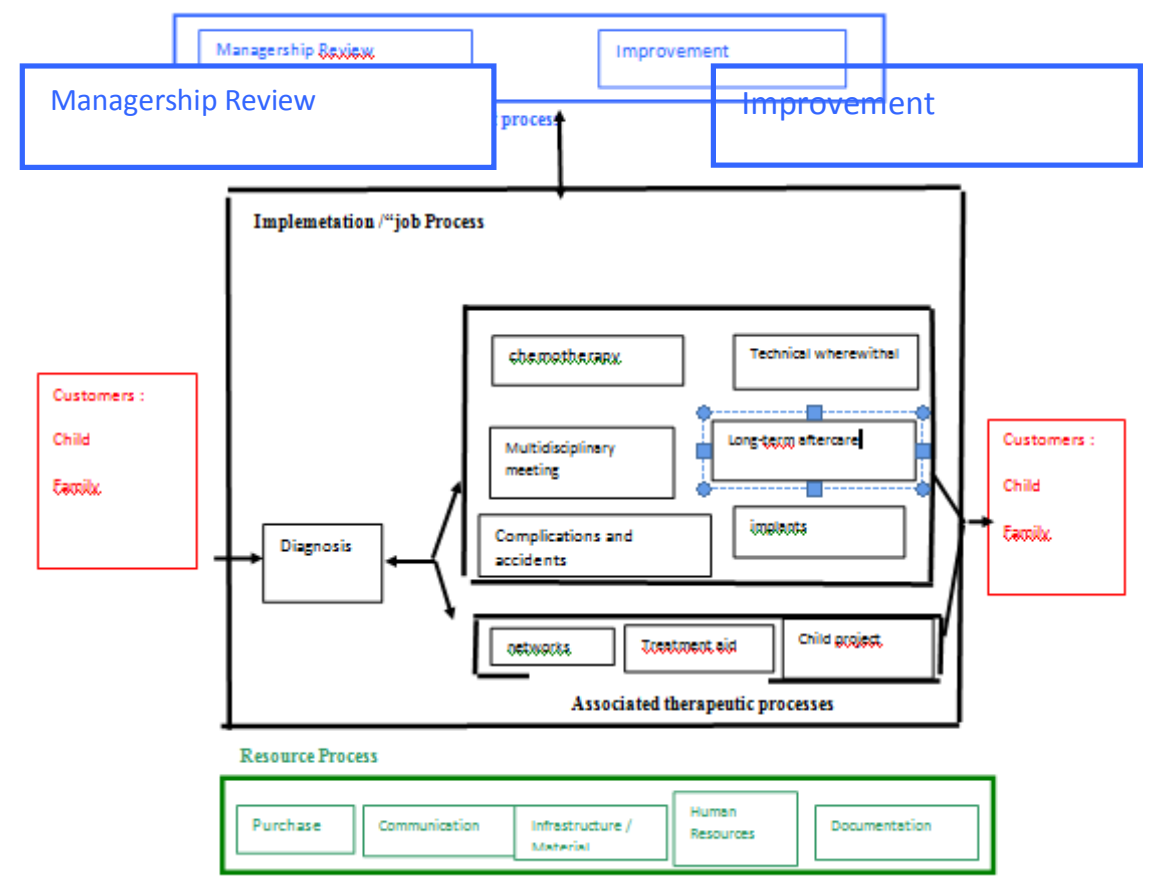

Figure 5: Mapping of quality management system in a pediatric oncology department (KANOLD, 2008). 